acute lymphoblastic leukemia presenting with paraparesis and multiple osteolytic lesions. Indian J Hematol Blood Transfus 2014;30(Suppl 1):24-6.

7. Fukasawa H, Kato A, Fujigaki Y, Yonemura K, Furuya R, Hishida A. Hypercalcemia in a patient with B-cell acute lymphoblastic leukemia: a role of proinflammatory cytokine. Am J Med Sci 2001;322:109-12.

8. Mahmood K, Ubaid M, Taliya Rizvi S. Multiple osteolytic lesions causing hypercalcemia: a rare presentation of acute lymphoblastic leukemia. Case Rep Med 2017;2017:2347810.

9. Inukai $\mathrm{T}$, Hirose $\mathrm{K}$, Inaba $\mathrm{T}$, et al. Hypercalcemia in childhood acute lymphoblastic leukemia: frequent implication of parathyroid hormone-related peptide and E2A-HLF from translocation 17;19. Leukemia 2007;21:288-96.

10. Heinrich SD, Gallagher D, Warrior R, Phelan K, George VT, MacEwen GD. The prognostic significance of the skeletal manifestations of acute lymphoblastic leukemia of childhood. J Pediatr Orthop 1994;14:105-11.

\section{Polycythemia vera emerging eighteen years after acute myeloid leukemia diagnosis}

TO THE EDITOR: Emergence of a JAK2 V617F-positive myeloproliferative neoplasm (MPN) while in remission from acute myeloid leukemia (AML) is an exceedingly rare phenomenon with the MPN presenting as polycythemia vera (PV), essential thrombocythemia or MPN unclassifiable [1-3]. Of these infrequently reported cases, retrospective analysis of AML diagnostic material has shown that the $J A K 2 \mathrm{~V} 617 \mathrm{~F}$ is sporadically present at this time demonstrating that this mutation can manifest phenotypically before or after AML presentation. Here we describe the clinical course of a patient in remission from AML in whom PV emerged eighteen years after initial diagnosis following fifteen years of disease free survival. We review those few similarly presenting cases from the $J A K 2 \mathrm{~V} 617 \mathrm{~F}$ era in order to identify any salient features.

A 64-year-old female with a long standing history of systemic lupus erythematosus presented in 2002 with lethargy, tiredness and a cough. Full blood count showed anemia $(\mathrm{Hb}, 11.6 \mathrm{~g} / \mathrm{dL})$, neutropenia $\left(0.2 \times 10^{9} / \mathrm{L}\right)$ and a normal plate-
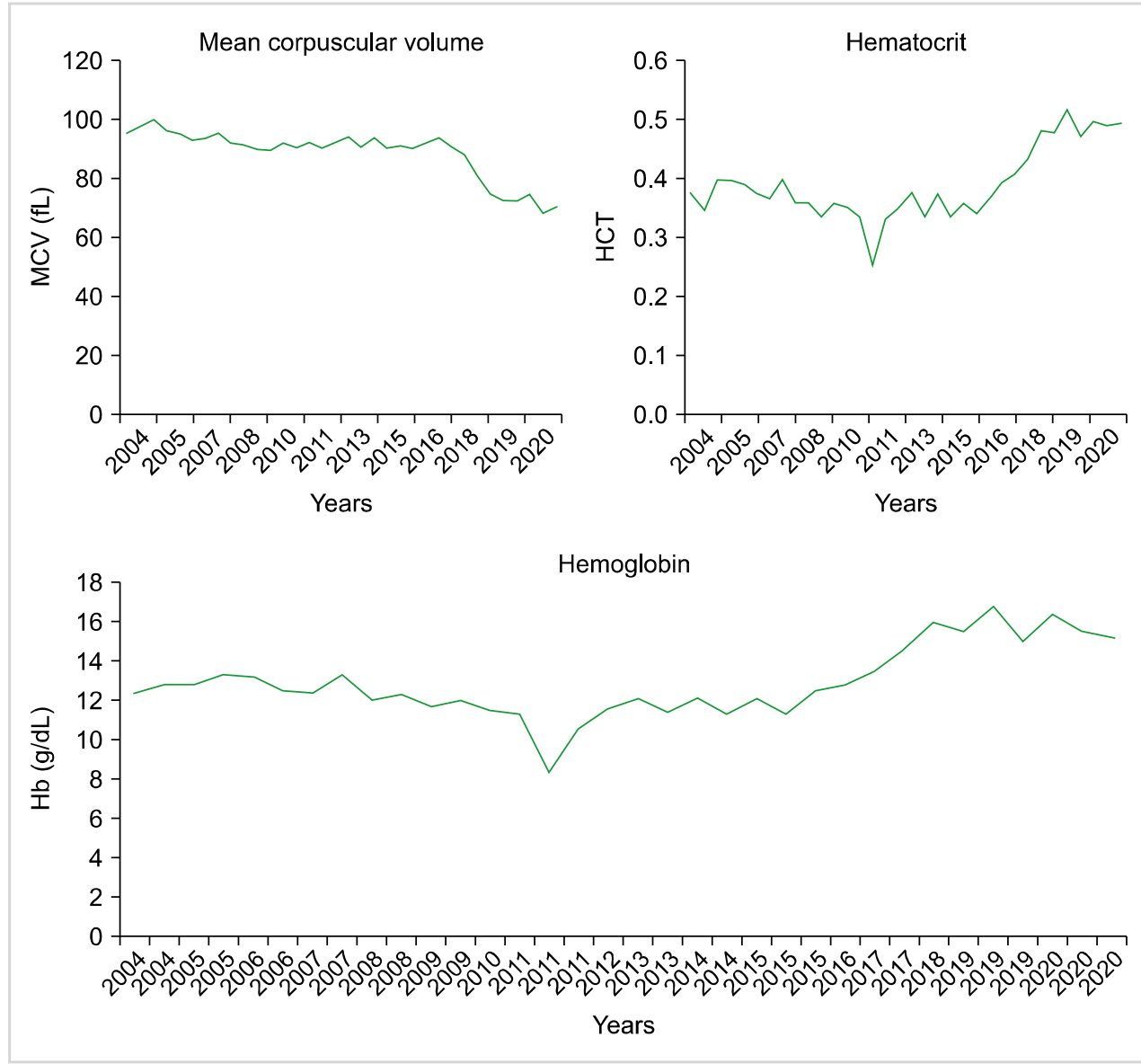

Fig. 1. Red blood cell indices of the patients throughout the clinical course. 
Table 1. Features of four cases of polycythemia vera emerging while in long-term remission from acute myeloid leukemia.

\begin{tabular}{|c|c|c|c|c|c|c|c|}
\hline Case reference & $\begin{array}{l}\text { Age at AML } \\
\text { diagnosis }\end{array}$ & Sex & AML type & $\mathrm{AML}$ treatment & $\begin{array}{l}\text { Time to PV from } \\
\text { AML diagnosis }\end{array}$ & $\begin{array}{c}J A K 2 \mathrm{~V} 617 \mathrm{~F} \text { at } \\
\text { AML } \\
\text { diagnosis }\end{array}$ & $\begin{array}{c}J A K 2 \mathrm{~V} 617 \mathrm{~F} \mathrm{VAF} \text { at } \\
\mathrm{PV} \\
\text { diagnosis }\end{array}$ \\
\hline Antonioli et al. [1] & 60 & M & M2 & $\begin{array}{l}\text { Flu/AraC/Ida } \times 1 \\
\text { Ida/Etop } \times 1 \\
\text { AutoSCT }\end{array}$ & $7 \mathrm{yr}$ & Not detected & $28 \%$ \\
\hline Belotti et al. [5] & 71 & M & M4 & $\begin{array}{l}\text { AraC/Ida/Etop } \times 1 \\
\text { Ida/AraC } \times 2 \\
\text { AraC } \times 2\end{array}$ & $7 \mathrm{yr}$ & Not done & Positive \\
\hline Portell et al. [6] & 59 & $\mathrm{~F}$ & M2 & $\begin{array}{l}\text { Ida/AraC } \times 1 \\
\text { AraC } \times 3\end{array}$ & $5 \mathrm{yr}$ & $2 \%$ & $91 \%$ \\
\hline This case & 64 & $\mathrm{~F}$ & M1 & $\begin{array}{l}\text { AraC/Daun } \times 8 \\
\text { Flu/AraC/Ida } \times 2\end{array}$ & $18 \mathrm{yr}$ & Not detected & $17 \%$ \\
\hline
\end{tabular}

Abbreviations: AML, acute myeloid leukemia; AraC, cytarabine; AutoSCT, autologous stem cell transplantation; Daun, daunorubicin; Etop, etoposide; Flu, fludarabine; Ida, idarubicin; M1, acute myeloid leukemia with minimal maturation; M2, acute differentiated myeloid leukemia; $\mathrm{M} 4$, acute myelomonocytic leukemia; VAF, variant allele frequency.

let count $\left(243 \times 10^{9} / \mathrm{L}\right)$. Bone marrow aspirate was predominantly infiltrated with Sudan Black-positive myeloblasts consistent with AML FAB type M1. The karyotype was normal with no evidence of splenomegaly identified. A recovery thrombocytosis of $903 \times 10^{9} / \mathrm{L}$ was noted after three courses of cytarabine and daunorubicin but was felt to be reactive and resolved. Review of archival bone marrow aspirates showed no morphological evidence of an MPN at this time. The patient relapsed in 2004 with 25\% CD13/CD33/ CD117+ myeloblasts in the bone marrow aspirate, normal spleen size and a normal karyotype. The patient was subsequently treated with two courses of FLAG-Ida (fludarabine, cytarabine, G-CSF, idarubicin) achieving complete remission with no rebound thrombocytosis. Blood counts were stable for more than a twelve years until 2017 when a slowly rising $\mathrm{Hb}$ and $\mathrm{HCT}$ accompanied by a microcytosis were noted and sustained until the present (peak Hb, 16.8 g/dL; peak HCT, 0.517; nadir MCV, $68.1 \mathrm{fL}$ ) (Fig. 1). The sustained erythrocytosis prompted $J A K 2$ mutation analysis in 2020 with the V617F mutation present at an allele burden of $17 \%$. Retrospective analysis of archival material from the time of AML presentation did not detect the JAK2 V617F. At last follow up the patient had not experienced any thrombotic or hemorrhagic episodes, had no palpable spleen, and was managed on low dose aspirin without any current requirement for venesection or cytoreduction.

The first case reported of PV developing from a background of AML was described in the pre-JAK2 V617F era [4]. A literature search reveals three previous cases of JAK2 V617F-positive PV developing while in long-term remission from AML with clinical features summarised in Table 1 $[1,5,6]$. All three patients had been previously treated intensively for AML with a maximum period of seven years to the development of PV. The case described herein is therefore noteworthy in the latency of eighteen years between AML diagnosis and documentation of JAK2 $\mathrm{V} 617 \mathrm{~F}$-positive disease that required clinical intervention.
The phenotypic manifestation of the JAK2 V617F, evidenced as the synchronous elevation in $\mathrm{Hb}$ and HCT and developing microcytosis is conspicuous, however it remains challenging to pinpoint when the mutation was acquired in the patients' hematopoietic stem cells. Population studies have proposed a low rate of increasing $J A K 2 \mathrm{~V} 617 \mathrm{~F}$ allele burden over many years though this expansion has also been shown to be highly variable in manifesting as an overt MPN [7, 8]. Intrinsically associated with the development of $\mathrm{PV}$ is the presence of the $J A K 2 \mathrm{~V} 617 \mathrm{~F}$ as a marker of clonal hematopoiesis in hematologically normal elderly individuals [9]. A common feature of these four patients is the age at which PV becomes apparent with a range of 64-82 years (Table 1 ). It may be speculated that intensive induction chemotherapy for AML and other hematological malignancies such as acute undifferentiated leukemia, acute lymphoblastic leukemia and diffuse large B-cell lymphoma [10-12] that result in ablation of the bone marrow microenvironment culminates in a niche compatible for pre-existing JAK2 V617Fpositive stem cells with clonal potential to inhabit and expand resulting as apparent PV.

While pre-clinical models of PV are valuable, standardized tools for dissecting the molecular mechanisms of the disease [13], unusual cases such as that described herein further emphasize the underlying clonal complexity of the development of JAK2 V617F-positve MPN.

Stephen E. Langabeer, Derick W. O'Flynn ${ }^{2}$, Mary R. Cahill ${ }^{2}$ ${ }^{1}$ Cancer Molecular Diagnostics, St. James's Hospital, Dublin, ${ }^{2}$ Department of Haematology, Cork University Hospital, Cork, Ireland

Correspondence to: Stephen E. Langabeer Cancer Molecular Diagnostics, Trinity Translational Medicine Institute, St. James's Hospital, Dublin, DOS W9RT, Ireland E-mail: slangabeer@stjames.ie 
Received on Feb. 24, 2021; Revised on Apr. 5, 2021; Accepted on Apr. 7, 2021

https:/doi.org/10.5045/br.2021.2021040

\section{Authors' Disclosures of Potential Conflicts of Interest}

No potential conflicts of interest relevant to this article were reported.

\section{REFERENCES}

1. Antonioli E, Guglielmelli P, Poli G, Santini V, Bosi A, Vannucchi AM. Polycythemia vera following autologous transplantation for AML: insights on the kinetics of JAK2 V617F clonal dominance. Blood 2007;110:4620-1.

2. Walker AR, Rothberg PG, Liesveld JL. A case of JAK2 positive essential thrombocythemia 16.5 years after autologous marrow transplantation for AML. Bone Marrow Transplant 2007;39: 725-6.

3. Sato S, Itonaga $\mathrm{H}$, Taguchi $\mathrm{M}$, et al. Clonal dynamics in a case of acute monoblastic leukemia that later developed myeloproliferative neoplasm. Int J Hematol 2018;108:213-7.

4. Chabannon C, Bost M, Hollard D. A case of polycythemia vera occurring in a patient with acute non-lymphoblastic leukemia (ANLL) in long-term first complete remission. Leukemia 1994;8:1243-4.

5. Belotti A, Doni E, Elli E, Rossi V, Pioltelli P, Pogliani EM. Development of polycythemia vera after chemotherapy-induced remission of acute myeloid leukemia: a case report. Acta Haematol 2011;126:52-3.

6. Portell CA, Sekeres MA, Rogers HJ, Tiu RV. De novo poly- cythaemia vera arising 5 years following acute myeloid leukemia remission: suggestion of a chemotherapy resistant JAK2 clone. Br J Haematol 2012;157:266-7.

7. Nielsen C, Bojesen SE, Nordestgaard BG, Kofoed KF, Birgens HS JAK2 V617F somatic mutation in the general population: myeloproliferative neoplasms development and progression rate. Haematologica 2014;99:1448-55.

8. McKerrell T, Park N, Chi J, et al. JAK2 V617F hematopoietic clones are present several years prior to MPN diagnosis and follow different expansion kinetics. Blood Adv 2017;1:968-71.

9. McKerrel T, Park N, Moreno T, et al. Leukemia-associated somatic mutations drive distinct patterns of age-related clonal hemopoiesis. Cell Rep 2015;10:1239-45.

10. Youk HJ, Cho CH, Lee JH, Choi CW, Lim CS, Yoon SY. A rare case of polycythemia vera following acute undifferentiated leukemia remission. Ann Lab Med 2014;34:469-70.

11. Sutherland ND, Gonzalez-Peralta R, Douglas-Nikitin V, Hunger SP. Polycythemia vera in a child following treatment for acute lymphoblastic leukemia. J Pediatr Hematol Oncol 2004;26: 315-9.

12. Elli EM, Belotti A, Cecchetti C, et al. Development of JAK2 V617F-positive polycythemia vera after chemotherapy-induced remission of primary central nervous system diffuse large B cell non-Hodgkin's lymphoma: a case report and review of the literature. Acta Haematol 2013;130:142-5.

13. Bartalucci N, Guglielmelli P, Vannucchi AM. Polycythemia vera: the current status of preclinical models and therapeutic targets. Expert Opin Ther Targets 2020;24:615-28. 